\title{
Mountain Torques and Northern Hemisphere Low-Frequency Variability. Part I: Hemispheric Aspects
}

\author{
FRANÇOIS LOTT \\ Laboratoire de Météorologie Dynamique, IPSL, Ecole Normale Supérieure, Paris, France \\ ANDREW W. Robertson* AND Michael GhiL ${ }^{+}$ \\ Department of Atmospheric Sciences, and Institute of Geophysics and Planetary Physics, University of California, Los Angeles, \\ Los Angeles, California
}

(Manuscript received 16 November 2001, in final form 20 November 2003)

ABSTRACT

\begin{abstract}
The NCEP-NCAR reanalysis dataset for 1958-97 is used to analyze intraseasonal variations in mountain torques and the large-scale atmospheric circulation patterns associated with them. Spectral analysis of the atmospheric angular momentum (AAM) budget shows that the dominant variations of mountain torque have periodicities near 30 days and shorter, while the dominant AAM variations occur in the 40-60-day band. This difference is due to the 40-60-day AAM variations being primarily related to equatorial processes, while mountain torque variations are associated mostly with extratropical processes.

The Northern Hemisphere $(\mathrm{NH})$ mountain torque has enhanced power and significant spectral peaks in the 20-30-day band. The signal in this band accounts for 33\% of the NH mountain torque variance, once the seasonal cycle has been removed. Lag composites of the $\mathrm{NH} \mathrm{700-hPa} \mathrm{geopotential} \mathrm{heights} \mathrm{based} \mathrm{on} \mathrm{the} \mathrm{20-30-day}$ mountain torque signal show the latter to be associated with coherent large-scale patterns that resemble lowfrequency oscillations identified in this band by previous authors. The composite patterns that are in phase quadrature with the 20-30-day NH mountain torque have a pronounced zonally symmetric component. These patterns are associated with substantial AAM variations, arguably driven by the $\mathrm{NH}$ mountain torque in this band.

Principal component (PC) analysis of the NH 700-hPa heights shows that, in the 20-30-day band, the mountain torque is also in phase quadrature with the two leading PCs; the first corresponds to changes in the midlatitude jet intensity near the subtropics, while the second corresponds to the Arctic Oscillation. The relationships with AAM of the latter essentially occurs through the mass term. Mountain torques are, furthermore, nearly in phase with dominant patterns of low-frequency variability that exhibit substantial pressure gradients across the Rockies and the Tibetan Plateau.
\end{abstract}

\section{Introduction and motivation}

During the last three decades, considerable research has been carried out on the low-frequency variability (LFV) of the atmosphere. In the extratropics, Blackmon (1976), Sawyer (1976), and others have found that the variance of the 500-hPa geopotential height is larger for the low-frequency part of the spectrum, with periods longer than 10 days, than for the higher-frequency part.

* Current affiliation: International Research Institute for Climate Prediction, Palisades, New York.

+ Additional affiliation: Départment Terre-Atmosphère-Océan and Laboratoire de Météorologie Dynamique, Ecole Normale Supérieure, Paris, France.

Corresponding author address: François Lott, Laboratoire de Météorologie Dynamique, Ecole Normale Supérieure, 24 rue Lhomond, 75235 Paris Cédex 05, France.

E-mail: flott@1md.ens.fr
This LFV is essentially contained in the planetary scales and is dominated by a few spatial patterns that can be effectively extracted by empirical orthogonal function (EOF) and cluster analysis (Ghil 1987; Mo and Ghil 1987; Molteni et al. 1988). Observational studies show that extratropical LFV is characterized by intermittent large-scale circulation regimes (Molteni et al. 1990; Cheng and Wallace 1993; Kimoto and Ghil 1993a,b), as well as by intraseasonal oscillations (Branstator 1987; Ghil 1987; Kushnir 1987; Ghil and Mo 1991; Plaut and Vautard 1994).

Several theoretical explanations of extratropical LFV have been given. Charney and DeVore (1979) pointed out that, in a low-order nonlinear quasigeostrophic model, the interaction of the flow with large-scale topography can give rise to multiple equilibria through topographic instability. More highly resolved models (Legras and Ghil 1985; Yoden 1985) produce more complex aspects of LFV, such as periodic and aperiodic solutions, 
suggesting that an oscillatory form of topographic instability also exists (Legras and Ghil 1985; Ghil 1987).

This theory of oscillatory topographic instability is supported by rather realistic general circulation model (GCM) runs (Marcus et al. 1994, 1996) and by rotating annulus experiments (Bernardet et al. 1990; Weeks et al. 1997; Tian et al. 2001). So far, direct observational support for oscillatory topographic instability has been fairly limited, but encouraging (Lott et al. 2001). Metz (1985), for instance, has found significant cross-spectral peaks between mountain torque $\left(T_{M}\right)$ and the zonal wind at periodicities above 15 days. Lejenäs and Madden (2000) have found links between Rossby waves, mountain torque, and atmospheric angular momentum (AAM) in the 6-15-day band. Intraseasonal variations in mountain torque have also been analyzed in connection with the AAM changes associated with the Madden and Julian (1971) oscillation in the Tropics (Madden 1987; Madden and Speth 1995).

Other theories attribute extratropical LFV to (i) a link between the Tropics and the extratropics through Rossby wave propagation (Hoskins and Karloy 1981), (ii) linear instabilities of the nonzonal climatological time-mean flow (Simmons et al. 1983), or (iii) the large-scale response to synoptic-scale transient eddy forcing (Hoskins et al. 1983; Illari and Marshall 1983; Vautard et al. 1988). In each of these approaches, large-scale mountains can contribute indirectly to extratropical LFV by maintaining a nonzonal mean state (Valdes and Hoskins 1991; Lott 1999) that also helps determine the stormtrack location (Hoskins and Valdes 1990).

Because of its global character and conservative properties, AAM is often used to study the variations of the general circulation on time scales of days to years. Several studies have linked AAM variations in the 40-60day band to the tropical intraseasonal oscillation with the same broad period (Madden 1987; Hendon 1995). The main physical link between the two is the frictional torque over the tropical Pacific Ocean. Weickmann et al. (1992) showed that, while this may be true during northern summer, mountain torque must play an important role during boreal winter.

Dickey et al. (1991) have demonstrated that, in fact, two statistically distinct peaks in AAM exist at 40 and at 50 days, and associated the 40-day peak with oscillatory topographic instability (Legras and Ghil 1985; Ghil 1987; Jin and Ghil 1990), while the 50-day peak exhibited characteristics of the Madden-Julian oscillation (MJO). More recently, Iskenderian and Salstein (1998) have shown that the midlatitude mountain torque is responsible for much of the high-frequency variations in AAM at periods below 14 days.

Iskenderian and Salstein (1998) and Lejenäs and Madden (2000) examined periods below 15 days, while Dickey et al. (1991) emphasized in their analysis periods above 35 days. Little attention, though, has been paid so far to the mountain torque in the intermediate 1535-day band. This is rather surprising since, in the $\mathrm{NH}$, significant cross-spectral peaks between mountain torque and vertically averaged zonal wind occur at periods above 15 days, while mountain torques also affect a blocking index at these time scales (Metz 1985). Furthermore, major extratropical oscillations (Branstator 1987; Kushnir 1987; Ghil and Mo 1991) occur in this band, in which the role of mountains is likely to be comparable at least with that of surface friction, especially in the NH. Moreover, the topographic obstacles that are so prominent in affecting the NH's quasi-stationary wave pattern (Charney and Eliassen 1949; Held 1983) are also likely to affect nonzonal LFV feature, beside the AAM and the zonally averaged westerly flow.

In this paper, we make use of $40 \mathrm{yr}$ (1958-97) of the National Centers for Environmental Prediction-National Center for Atmospheric Research (NCEP-NCAR) reanalysis dataset (Kalnay et al. 1996) to study mountain torque variations in the 15-35-day band and relate them to major features of extratropical LFV, both zonal and nonzonal. The statistically most significant relationships are found at periodicities ranging from 20 to 30 days, and are thus quite distinct from those documented in previous studies of the AAM budget. These periodicities are well separated from the tropical oscillation's dominant periodicity of 50 days, and we can thus confidently attribute them to processes that originate primarily in the midlatitudes.

To verify that NH mountains influence LFV directly, rather than just via forcing the quasi-stationary planetary waves, it is necessary to establish statistically significant and physically coherent links between the mountain torques and the dominant patterns of extratropical LFV. In this perspective we emphasize in our results the mountain torque signals that precede changes of well-known LFV patterns, like the Arctic Oscillation (Thompson and Wallace 1998; Wallace 2000). Conversely, our observational study also addresses the way that large-scale patterns affect mountain torque variations at the dominant frequencies where this particular term of the AAM budget varies.

The present paper represents the first part of a twopart study on the relationship between $\mathrm{NH}$ mountain torques and LFV. In section 2 we present the reanalysis data, compute the global AAM budget, and examine the spectra of the different terms in the budget. In section 3 we present the spatiotemporal structure of the hemispheric flow fields associated with the dominant peaks of the NH mountain torque. To determine if these fields are linked to dominant low-frequency patterns, a spectral analysis of the leading principal components (PCs) of the $700-\mathrm{hPa}$ geopotential heights is carried out in section 4 . We then investigate the hemispheric relationships between the mountain torque and the dominant low-frequency patterns. Concluding remarks to Part I follow in section 5. Regional aspects of these relationships are studied in Part II (Lott et al. 2004). 


\section{Data and methods}

Our data are derived from the NCEP-NCAR reanalysis that spans the 40 years from 1958 to 1997 (Kalnay et al. 1996). Specifically, we use the daily averages of the surface pressure field $P_{s}$, the 700-hPa geopotential heights, and the zonal wind $u$ at the 19 pressure levels given by the analysis. We also use the daily average of the boundary layer stress $\tau_{B}$ issued from 6-h forecasts. To reduce the number of points in each of these time series, we form 3-day nonoverlapping box-car averages, a procedure that was verified not to affect the spectra for periods that exceed 10 days. In the following these 3 -day-averaged series are referred to as the " $3 \mathrm{~d}$ " series, while the series of daily averages are referred to as the "daily" series.

To focus attention on the intraseasonal band, a bandpass filter is applied to the daily series when needed. This intraseasonal filter is obtained by applying first a highpass and then a low-pass filter. The resulting filter strongly attenuates the annual and semiannual cycles, as well as the fluctuations with periods below 10 days. The highpass filter is due to Papoulis (1973) and applies to the daily series the minimum-bias taper $W_{0}(t)$, with

$$
W_{0}(t)= \begin{cases}\frac{1}{\pi}\left|\sin \frac{\pi t}{L}\right|+\left(1-\frac{|t|}{L}\right) \cos \frac{\pi t}{L}, & \text { for }|t|<L ; \\ 0, & \text { for }|t|>L .\end{cases}
$$

A choice of maximum lag $L=90$ gives the half-power point of the frequency window associated with $W_{0}(t)$ at 150 days. To filter out the synoptic transient eddies, we applied next the low-pass filter developed by Blackmon and Lau (1980), whose half-power point is around 10 days. The resulting time series are referred to as intraseasonal (IS) series, and are sampled every 3 days.

\section{a. Atmospheric angular momentum budget}

The global AAM tendency budget is given by

$$
\frac{d M}{d t}=T,
$$

where

$$
\begin{gathered}
M=M_{R}+M_{\Omega}, \\
T=T_{M}+T_{B} .
\end{gathered}
$$

Here, $M$ and $T$ are the absolute angular momentum and the total torque respectively, while $M_{R}, M_{\Omega}, T_{M}$, and $T_{B}$ are the relative angular momentum, the planetary angular momentum, the torque due to the mountains, and the torque due to the boundary layer stress $\tau_{B}$, respectively. The latter four quantities are computed as

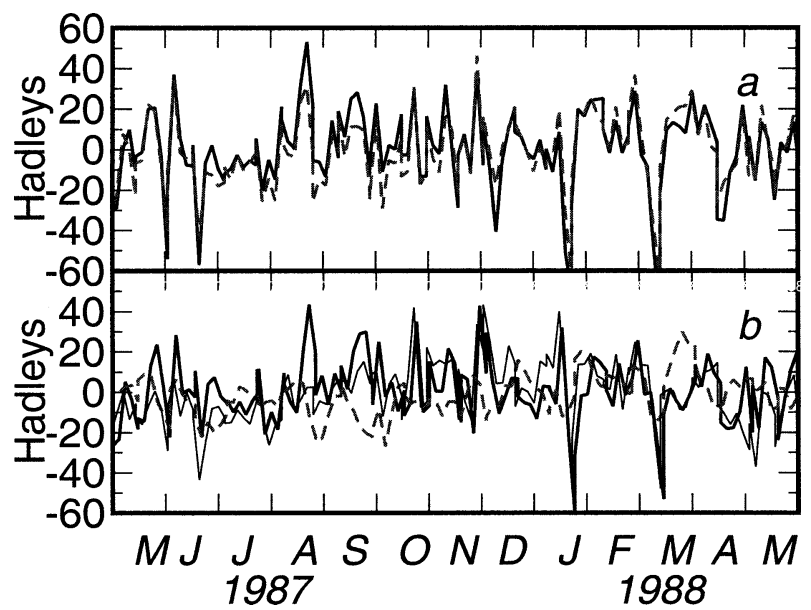

FIG. 1. Atmospheric angular momentum balance and torques over one year. (a) Global AAM tendency (heavy solid) and total torque (dashed); (b) global mountain torque (heavy solid), frictional torque (dashed), and Northern Hemisphere mountain torque (light solid).

$$
\begin{aligned}
M_{R} & =\int_{0}^{P_{0}} \int_{0}^{2 \pi} \int_{-\pi / 2}^{\pi / 2} r^{3}(\cos \theta)^{2} u d \theta d \lambda \frac{d p}{g}, \\
M_{\Omega} & =\int_{0}^{2 \pi} \int_{-\pi / 2}^{\pi / 2} \frac{r^{4} \Omega}{g}(\cos \theta)^{3} P_{s} d \theta d \lambda \\
T_{M} & =-\int_{0}^{2 \pi} \int_{-\pi / 2}^{\pi / 2} r^{2}(\cos \theta) P_{s} \frac{\partial Z_{s}}{\partial \lambda} d \theta d \lambda \\
T_{B} & =\int_{0}^{2 \pi} \int_{-\pi / 2}^{\pi / 2} r^{3}(\cos \theta)^{2} \tau_{B} d \theta d \lambda .
\end{aligned}
$$

In the integrals of Eqs. (5)-(8), $\lambda$ is longitude, $\theta$ is latitude, $p$ is pressure, $u$ is the zonal wind, $g$ the acceleration of gravity, $r$ is the mean radius of the earth, $P_{0}=1000 \mathrm{hPa}, P_{s}$ is the surface pressure, $Z_{s}$ the topographic height, $\Omega$ the angular velocity of the earth's rotation, and $\tau_{B}$ the surface boundary layer stress. For the mountain torque, the contribution of the NCEP model's parameterized mountain gravity waves was not included because it degrades the balance between the global AAM tendency and the torques (Huang et al. 1999).

Figure 1a shows the global AAM budget for the interval between 1 May 1987 and 31 May 1988 expressed in hadleys $\left(1 \mathrm{H}=10^{18} \mathrm{~kg} \mathrm{~m}^{2} \mathrm{~s}^{-2}\right)$, based on the $3 \mathrm{~d}$ series. The tendency $d M / d t$ shown here is very similar to the independent estimate of Madden and Speth (1995), based on ECMWF data. The total torque $T_{M}+$ $T_{B}$ follows $d M / d t$ very closely: their correlation coefficient is $r=0.87$.

Figure $1 \mathrm{~b}$ compares $T_{M}$ and $T_{B}$ and shows that the $3 \mathrm{~d}$ series of both torques have comparable amplitude, with larger but short-lived spikes present in the mountain torque. Overall, the large fluctuations in $T_{M}$ occur on faster time scales than those in $T_{B}$ : the decorrelation time scale of $T_{M}$ is near 2 days and that of $T_{B}$ is near 
6 days [see also Weickmann et al. (2000) and Egger and Hoinka (2002)].

Figure $1 \mathrm{~b}$ also shows separately the $\mathrm{NH}$ mountain torque, where the $\mathrm{NH}$ data are taken here between $20^{\circ}$ and $90^{\circ} \mathrm{N}$. The $\mathrm{NH} T_{M}$ tracks the total mountain torque fairly closely, which is consistent with the fact that the major mountains are located in the $\mathrm{NH}$ : over the full 40 -yr interval of our dataset, the variances of the two series, $T_{M}$ and NH $T_{M}$, are comparable. Their correlation is above $r=0.7$ and exceeds $r=0.8$ when restricted to the IS band. Note, nevertheless, that there are major spikes in $T_{M}$ due to the Andes, which have no counterpart in NH $T_{M}$.

Figure 2 shows the atmospheric pattern, $\tilde{Z}$, associated with the IS mountain torque variations. It is obtained by regressing the IS $700-\mathrm{hPa}$ geopotential height maps $Z_{700}=Z_{700}(\lambda, \theta, t)$ onto the IS NH mountain torque, over the entire $40-\mathrm{yr}$ interval. The $\mathrm{NH}$ mountain torque variations in Fig. 2 are associated with two east-west dipole structures in the $Z_{700}$ height field that extend across the Rockies and the Himalayas, respectively. The northsouth axes of the two dipoles are located along the western (upwind) flanks of these two mountain chains. According to this regression map, when the torque is positive, the most prevalent pattern has two lows centered over the northeastern Pacific and northeastern Europe, respectively. It also has two highs, centered over western and central North America and Siberia, respectively. The NH mountain torque results from the zonal pressure gradients along the western flanks of the Rockies and Himalayas that are associated with these patterns.

\section{b. Spectral analysis of the AAM budget}

To determine whether any statistically significant oscillations affect the 40-yr time series of the mountain torque and of the other AAM budget components, we compute the spectra of each term in Eqs. (2)-(4).

The power spectrum of the mountain torque (Fig. 3a) has an almost white background together with an annual and a semiannual cycle. It exhibits a relative deficit in amplitude at periodicities between 40 days and 180 days, a band where no peak passes the $95 \%$ confidence level. At periodicities below 35 days it increases in amplitude and contains four peaks in the 15-30-day band, all of which are significant at the $99 \%$ level.

We evaluated the robustness of the spectrum in Fig. 3a by computing the spectra of the first and second halves of the NH $T_{M} 3 \mathrm{~d}$ data. When using the same parameters as in Fig. 3a, the two resulting spectra (not shown) have much in common with the one evaluated using the complete time series. They both indicate a near-white background with a relative deficit in the 40180-day band, and two to four peaks in the 15-30-day band that are significant at the $99 \%$ level.

The spectrum of the relative angular momentum $\left(M_{R}\right)$ tendency is shown in Fig. 3c. Like the mountain torque, it has a near-white background but shows significant peaks at 40 and 50 days, in agreement with Dickey et al. (1991) and Penland et al. (1991). These two peaks are either absent (50 days) or marginally significant (40 days) in the mountain torque spectrum of Fig. 3a; the 50-day peak is known to be linked to the MJO (see also Madden 1987). In addition, Fig. 3c contains significant peaks at periods near 30 days and shorter; these peaks agree quite well with those of the mountain torque in Fig. 3a.

The mismatch between the spectra of the $M_{R}$ tendency and the mountain torque $T_{M}$ between the periods of 40 and 100 days has to be compensated by contributions from either the boundary layer torque $\left(T_{B}\right)$ or the planetary angular momentum $\left(M_{\Omega}\right)$ tendency. This point is tested in Figs. $3 \mathrm{~b}$ and $3 \mathrm{~d}$, which show the spectra of these two quantities, respectively.

The $M_{\Omega}$ tendency (Fig. 3d) has even less power than the $M_{R}$ tendency at periods above 40 days and contributes to the AAM balance at higher frequencies than the latter, while $T_{B}$ (Fig. $3 \mathrm{~b}$ ) exhibits much more power at periods above 30 days than below. In particular, it has a broad and highly significant peak at 38-40 days that is prominent here in the $M_{R}$ tendency spectrum (Fig. 3c). The 50-day peak in $M_{R}$ tendency (Fig. 3c) can be associated with a broad peak at 50 days in the total torque $\left(T_{M}+T_{B}\right)$ spectrum that is significant at the $95 \%$ level (not shown).

The novel result in Fig. 3a is that the most pronounced signals that can be detected in mountain torque alone are at periodicities close to 30 days and below. These $T_{M}$ variations cannot, therefore, be related primarily to the Tropics, which are dominated by oscillations around 50-60 days and commonly associated with the MJO.

\section{Dominant composite patterns in the NH}

\section{a. The 20-30-day NH torque signal}

To describe the midlatitude atmospheric oscillations associated with topographic effects, we focus now on the NH. The spectrum of the NH mountain torque (Fig. 4a) exhibits the same deficit in the 40-180-day band as the global mountain torque in Fig. 3a: it has four peaks in the 15-30-day range that are significant at the 99\% level and none between 35 and 180 days. Again, we checked that the overall shape of this spectrum remains unchanged when the dataset is divided into two halves (not shown). Although the exact location and relative amplitude of the significant peaks vary a little from one spectrum to the other, we systematically find significant peaks in the 20-30-day band and none at periodicities above 35 days. In the following, we take these peaks as evidence that the $\mathrm{NH}$ mountain torque is related to the large-scale, low-frequency oscillations that are known to occur in the NH midlatitudes over the same range of frequencies (Branstator 1987; Kushnir 1987; Ghil and Mo 1991; Plaut and Vautard 1994).

We isolate the NH mountain torque in the 20-30-day 


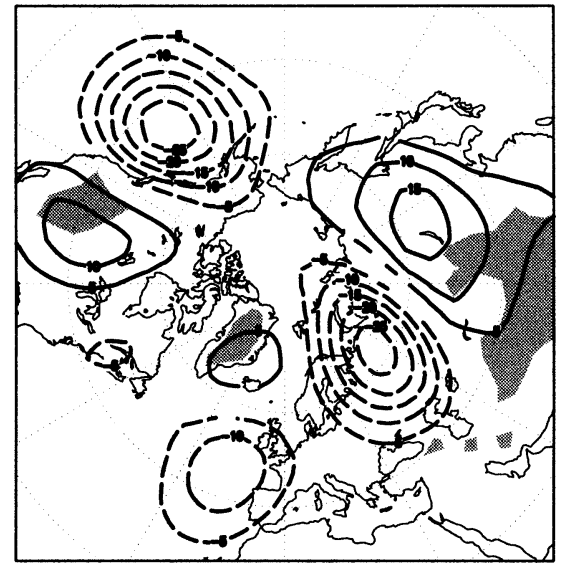

FIG. 2. The 700-hPa geopotential height field regression with respect to the $\mathrm{NH}$ mountain torque in the intraseasonal band; altitudes above $1500 \mathrm{~m}$ are shaded. Positive contours are solid, negative ones are dashed; contour interval is $5 \mathrm{~m}$. See Figs. 2a,b in Part II for the corresponding regressions with respect to the Rockies and the Himalayas torques, separately.

a) Mountain torque

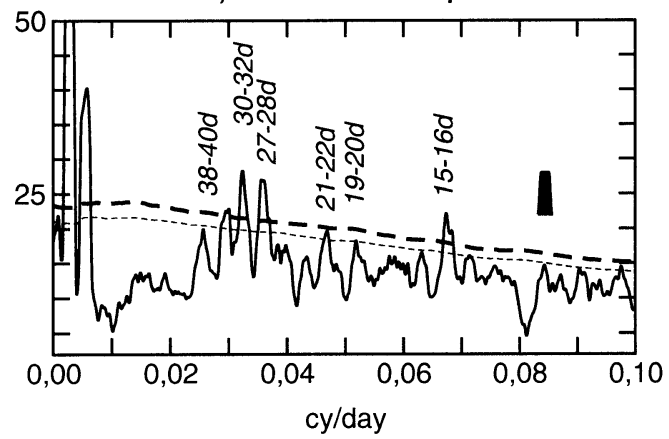

c) Relative AAM tendency

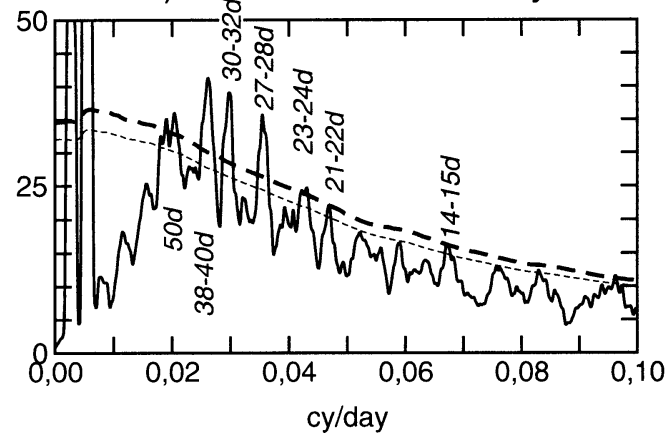

band by using a nonrecursive bandpass filter that uses Kaiser windows with parameters adjusted to minimize Gibbs effects (Hamming 1983a,b; Scavuzzo et al. 1998). The transfer function of this filter is displayed in Fig. $4 \mathrm{~b}$; it is very close to unity between 17 days and 33 days and nearly zero above 50 days and below 14 days. In the following, all daily series filtered this way, and sampled every 3 days, will be referred to as 20-30-day series.

For the NH $T_{M}$, the 20-30-day series (not shown) matches very well, in phase and amplitude, the IS series: the correlation between the two is around 0.8 . The 2030 -day series accounts typically for $45 \%$ of the variance of the IS series and $25 \%$ of the variance of the $3 \mathrm{~d}$ series (33\% when the annual cycle is subtracted) (see Table 1 , where these numbers are given for the different series).

b. NH circulation associated with the 20-30-day $\mathrm{NH} \mathrm{T}_{\mathrm{M}}$

Figures 5a-d show composites of hemispheric geopotential heights at $700 \mathrm{hPa}$ that are associated with the

\section{b) Boundary layer torque}

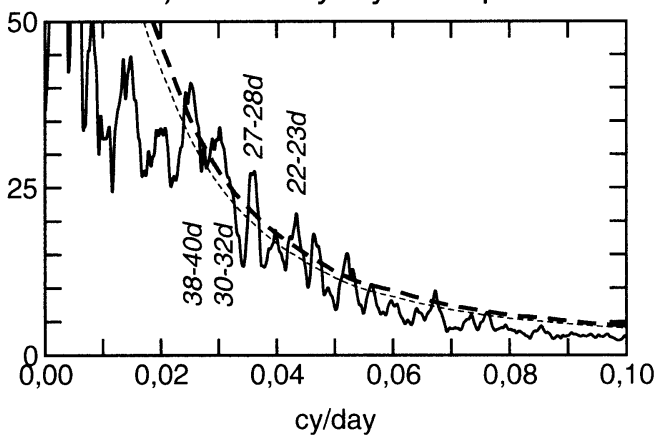

d) Planetary AAM tendency

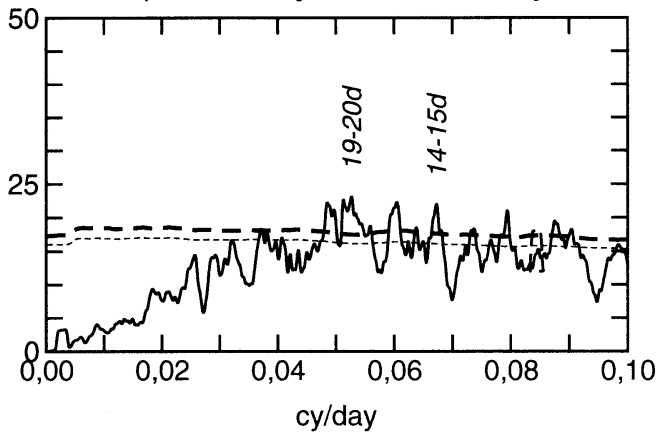

FIG. 3. (a)-(d) Spectra of the different terms in the AAM budget; see Eqs. (2)-(8). All curves are normalized by the mountain torque variance with annual cycle subtracted. The spectra (solid curve) are obtained by taking the Fourier transform of the $3 \mathrm{~d}$ series, and by smoothing the resulting periodogram with a 33\% cosine 30-point window [shown as the filled curve in (a)]. This window yields a frequency resolution of $2.3 \times 10^{-3}$ cycles per day. The heavy and light dashed lines show the $99 \%$ and $95 \%$ significance level of a Monte Carlo test based on the spectra of 100 realizations of an AR-1 process whose variance and lag-1 autocorrelation were least squares-fitted to the $3 \mathrm{~d}$ series with annual cycle subtracted. 
a) Spectrum

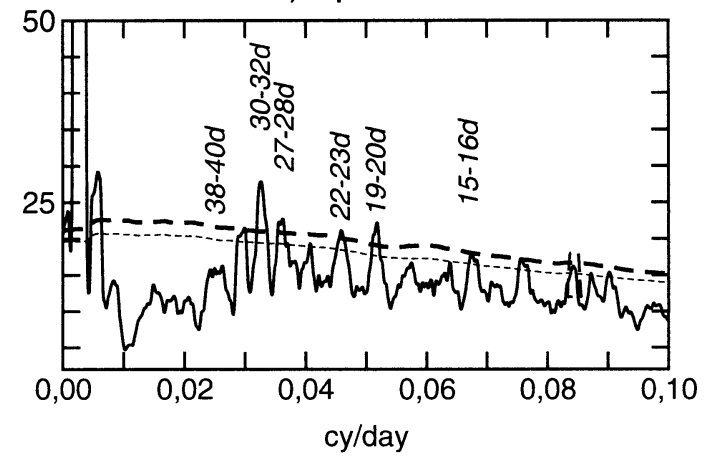

b) Transfer function

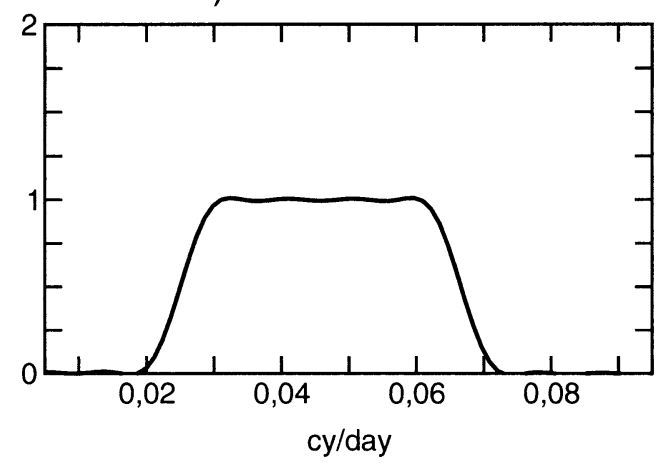

FIG. 4. NH mountain torque. (a) Spectrum of the $3 \mathrm{~d}$ series, same parameters and normalization as in Fig. 3; (b) transfer function of the bandpass filter used to extract the 20-30-day series.

20-30-day NH $T_{M}$. These composites are built from $Z_{700}$ maps in the IS band, selected when the 20-30-day NH mountain torque presents a local extremum that exceeds in amplitude a given threshold. At zero lag, for instance (Fig. 5a), the composite is the sum of the IS $Z_{700}$ maps corresponding to dates when the $\mathrm{NH} T_{M}$ exceeds the prescribed threshold, minus the sum of the IS $Z_{700}$ maps corresponding to dates when the $\mathrm{NH} T_{M}$ has a local minimum that is below minus that threshold. As the number of positive charts selected is always near that of negative ones, the composite map is then divided by $N_{c}$, the total number of extrema in NH $T_{M}$ selected. At a given nonzero lag, the composites are built with those maps that each corresponds to a date situated at the given lag from a local extremum identified before in the 20-30-day NH $T_{M}$. Note that the threshold value is arbitrary, and the number $N_{c}$ decreases when the threshold increases. We have verified, though, that the composite spatial patterns are not sensitive to moderate changes in the threshold. The threshold value $17 \mathrm{H} \approx 1.7 \sigma_{T}$, where $\sigma_{T}$ is the standard deviation of the IS NH mountain torque, is used in Fig. 5; in this case, $N_{c}$ is near 80.

In Figs. 5a-d, only half a cycle is shown since the
TABLE 1. Percentage of variance in each series accounted for by the 20-30-day series used in the text.

\begin{tabular}{llcrcc}
\hline \hline & & All year & DJF & No annual & IS \\
\hline NH & $T_{M}$ & 23 & 32 & 33 & 44 \\
Global & $M$ & 4 & 9 & 15 & 21 \\
NH & PC 1 & 1 & 18 & 22 & 37 \\
NH & PC 2 & 13 & 16 & 25 & 28 \\
NH & PC 5 & 25 & 30 & 37 & 40 \\
\hline
\end{tabular}

anomaly patterns in the second half are similar in shape and of opposite sign to those in the first half. Areas that equal or exceed a 95\% Monte Carlo test for the significance of the anomalies are shaded. The test uses an ensemble of 100 surrogate anomaly composite maps, constructed by averaging $N_{c}$ height anomalies maps chosen at random.

At zero lag with respect to the extrema of $\mathrm{NH} T_{M}$ (Fig. 5a), the composite essentially shows a low west of the Rockies and an east-west dipole northwest of the Himalayas. These two features correlate well with large torques over the Rockies and the Himalayas, respectively (see Figs. $2 \mathrm{a}$ and $2 \mathrm{~b}$ in Part II) and give rise to a large NH torque according to Fig. 2. At 3-day lag (Fig. 5b) the anticyclonic anomalies have decayed in area, while the cyclonic anomalies have grown. At 6day lag (Fig. 5c), that is, at the time of approximate quadrature with the $\mathrm{NH}$ torque, the patterns are predominantly cyclonic; they correspond to positive zonal wind anomalies in the midlatitudes. At that time, the zonal average of the $Z_{700}$ composites (not shown) is nearly everywhere negative in the $\mathrm{NH}$; this average also decreases monotically from near $0 \mathrm{~m}$ at $20^{\circ} \mathrm{N}$ to a minimum of $-25 \mathrm{~m}$ near $65^{\circ} \mathrm{N}$. At 9-day lag (Fig. 5d), eastwest dipoles start to build up over the Rockies and along the western flank of the Tibetan Plateau; their polarity is opposite to the pattern in Fig. 2 and thus results in a negative torque.

From a more regional viewpoint it is noteworthy that the cyclonic anomaly located to the west of the Rockies at 0-day lag in Fig. 5a shifts westward as the lag increases (Figs. 5b-d). In Fig. 5c, the anomaly patterns correspond, by geostrophy, to zonal wind anomalies that are near $5 \mathrm{~m} \mathrm{~s}^{-1}$ in the central Pacific and between $40^{\circ} \mathrm{N}$ and $50^{\circ} \mathrm{N}$. The composites also systematically exhibit significant anomalies over the North Atlantic sector. At zero lag (Fig. 5a) they consist of a north-south dipole with an anticyclonic anomaly centered over Greenland; such a $Z_{700}$ pattern is associated with a weakened jet over the northeastern Atlantic. As lag increases, this dipole moves poleward, and a cyclonic anomaly is established over Greenland at 6- and 9-day lag (Figs. $5 \mathrm{c}, \mathrm{d})$.

To corroborate that the patterns in Fig. 5 are associated with substantial changes in AAM that are driven by the NH $T_{M}$, Fig. 6 shows composites of the different terms of the AAM budget. They are built from the IS series of $M$ and NH $T_{M}$ using the $N_{c}$ days selected in 



FIG. 5. Composite anomalies of $Z_{700}$ maps from the IS time series keyed to the 20-30-day signal of NH mountain torque: (a) 0-day lag, (b) 3-day lag, (c) 6-day lag, and (d) 9-day lag. Contour interval: $10 \mathrm{~m}$; positive values, heavy solid; negative values, heavy dashed; $95 \%$ confidence, shaded; continental contours, light solid. The days for each composite cycle are counted from the local extremum of the 20-30-day NH $T_{M}$ for that cycle (see text for details).

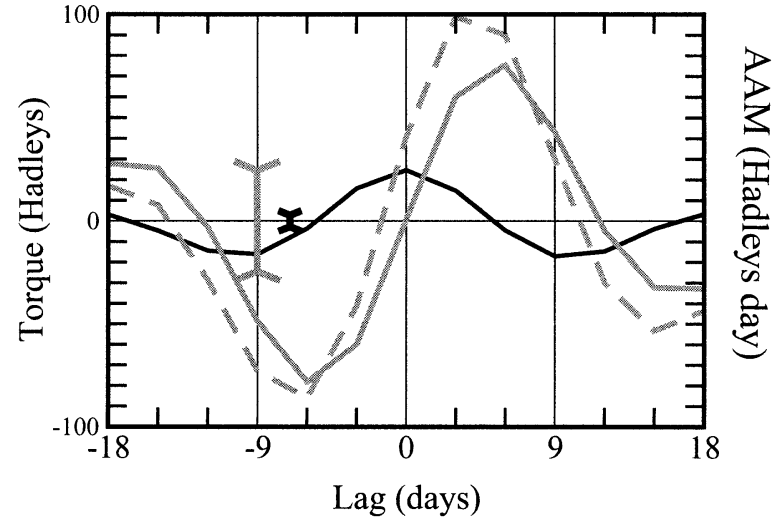

FIG. 6. Composites of different terms in the AAM budget during the composite cycle illustrated in Fig. 5: IS NH $T_{M}$ (black solid); integral of IS NH $T_{M}$ (gray solid); and global IS $M$ (gray dashed). Units for the global atmospheric angular momentum $M$ are in hadley day: $1 \mathrm{H} \mathrm{d}=8.6410^{22} \mathrm{~kg} \mathrm{~m}^{2}$. The vertical black bar and the vertical gray bar indicate the $95 \%$ confidence interval of a Monte Carlo test for the torque and for the global AAM, respectively.
Fig. 5. The 95\% confidence levels are from a Monte Carlo test, constructed as for the $Z_{700}$ composites but using the IS NH $T_{M}$ and $M$ series to compute surrogate averages of these quantities. The $\mathrm{NH}$ mountain torque composite (black solid line in Fig. 6) has a maximum of $24 \mathrm{H}$ at 0 -day lag, surrounded by two minima near $-20 \mathrm{H}$ at -9 day and +9 day lag, respectively. These three extrema are significant at the $95 \%$ level. They are also quite substantial when compared to the standard deviation $\sigma_{T}$ of the IS NH $T_{M} ; \sigma_{T} \approx 10 \mathrm{H}$.

The AAM response to be expected from this NH $T_{M}$ composite can be evaluated by integrating the latter composite in time (solid gray line in Fig. 6, where it is expressed in hadley day: $1 \mathrm{H} \mathrm{d}=8.64 \times 10^{22} \mathrm{~kg} \mathrm{~m}^{2}$ ). This response is also quite substantial; it exhibits two extrema of opposite signs and equal to approximately $\pm 75 \mathrm{Hd}$, while the IS $M$ standard deviation $\sigma_{M}$ is about $100 \mathrm{Hd}$. The gray dashed line in Fig. 6 denotes the composite of the IS $M$ and behaves very much like the integral of the mountain torque composite. An even better fit could be obtained by adding the boundary layer torque for the NH, NH $T_{B}$, to the $\mathrm{NH} T_{M}$. Although the 
NH $T_{B}$ composites are small in amplitude, the small phase shift at zero-day lag between the composite IS $M$ and the integral of the torque vanishes for the total NH torque, $\mathrm{NH} T_{M}+\mathrm{NH} T_{B}$ (not shown). This confirms the result of Weickmann et al. (2000), who found, emphasizing the stochastic aspects of the AAM budget, that the mountain torque produces the AAM anomalies, while the friction torque damps them.

Over the Pacific sector, our coherent large-scale 2030-day circulation patterns are consistent with those obtained by more direct methods (Branstator 1987; Kushnir 1987; Ghil and Mo 1991). These authors have shown that, during certain winters, NH variability in the Pacific can be dominated by large-scale oscillations in this band. At least the nonzonal part of the composites in Fig. 5 has much in common with the Branstator-Kushnir oscillation in which a large circulation anomaly over the Pacific propagates slowly westward. Note that this westward propagation is an additional indication that the sequence of maps in Fig. 5 cannot be primarily related to the MJO, which exhibits eastward propagation (Madden and Julian 1994).

Over the Atlantic sector the anomaly patterns in Figs. 5a and 5d correlate well with Wallace and Gutzler's (1981) North Atlantic Oscillation (NAO), whose spectrum is known to have some power at periodicities near 30 days (Plaut and Vautard 1994). The latter authors have shown that the NAO mode of LFV is also associated with anomalies that originate over northeastern Europe; hence it is not surprising here to find it linked with the mountain torque via the Himalayas (see Fig. 2).

\section{Principal components of hemispheric LFV \\ a. PC analysis}

The dominant patterns of atmospheric variability can be captured by projecting it onto the subspace formed by its leading spatial EOFs (Preisendorfer 1988). We take the 3-day mean $Z_{700}$ maps over the $40 \mathrm{yr}$ of record and compute EOFs over the NH.

The first EOF (Fig. 7a) accounts for $47 \%$ of the $3 d$ variance; it exhibits a strong zonal symmetry and describes changes in midlatitude zonal wind intensity and mass distribution that are associated primarily with the seasonal cycle. Its contribution to the variance over the boreal winter months (DJF), only equals $3.7 \%$. This EOF-1 is likely to be associated with variations in relative angular momentum $M_{R}$, because it is zonally symmetric and changes monotonically with latitude: using in Eq. (5) the value for $u$ deduced by geostrophy from Fig. 7a and multiplying the result by the standard deviation of the IS PC-1 gives characteristic $M_{R}$ variations near $25 \mathrm{Hd}$. It can also be associated with variations in planetary angular momentum $M_{\Omega}$, as the change in mass it describes in the $\mathrm{NH}$ extratropics has to be equilibrated by an opposite change in mass in the equatorial band.

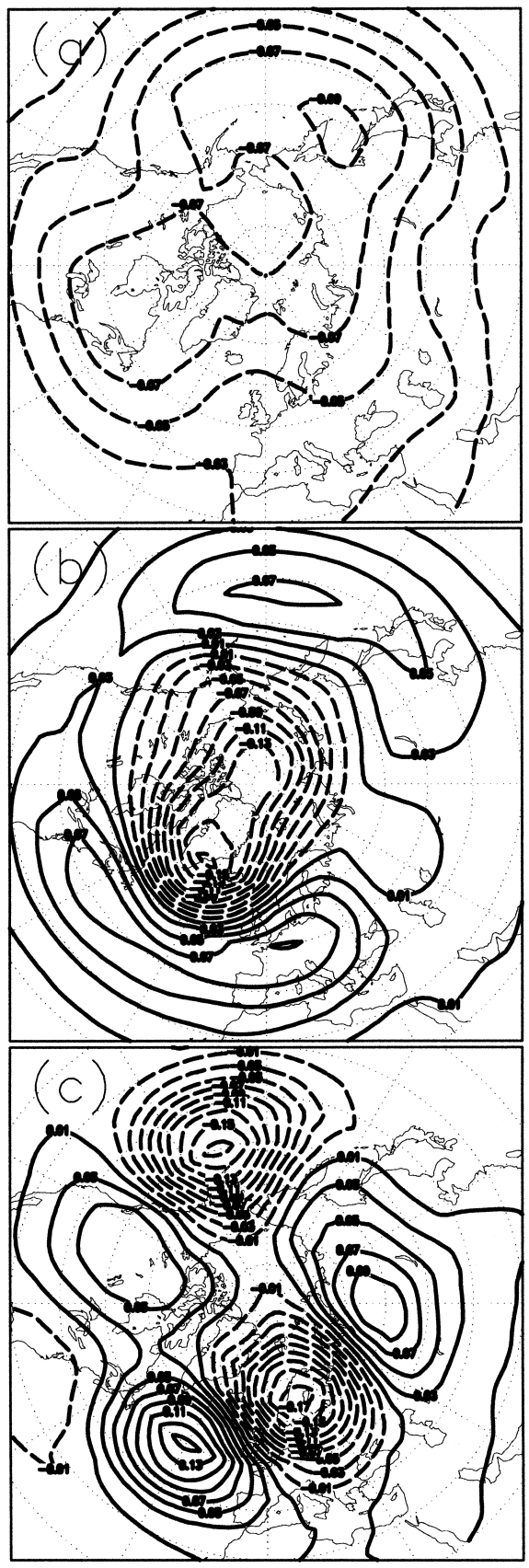

FIG. 7. NH EOFs of the 700-hPa geopotential height field: (a) EOF-1, (b) EOF-2, and (c) EOF-5.

The second EOF (Fig. 7b) accounts for $6 \%$ of the $3 d$ variance and is dominated by the Arctic Oscillation pattern (Thompson and Wallace 1998); it is very similar to the first winter EOF (not shown) and accounts for $12 \%$ of the DJF variability. EOF-2 is fairly zonally symmetric, too, but exhibits a change in sign in midlatitudes, with one extensive and intense negative feature spreading over the Arctic and two separate positive centers over the North Atlantic and central North Pacific oceans. It thus contributes less than EOF-1 to changes in relative 
angular momentum but is nevertheless associated with a redistribution of mass from northern to subtropical latitudes, which can make it contribute to changes in planetary AAM (von Storch 1994, 1999). Using in Eq. (6) the value for $P_{s}$ deduced by hydrostatic balance from Fig. 7b taking for density at $850 \mathrm{hPa} \rho_{r}=1 \mathrm{~kg} \mathrm{~m}^{-3}$, and multiplying the result by the standard deviation of the IS PC-2, gives characteristic $M_{\Omega}$ variations of about $12.5 \mathrm{Hd}$.

The lower-ranked EOFs $(3,4,5, \ldots)$ do not have a clear interpretation in a hemispheric analysis since they are all combinations of regional patterns. Their links with the mountain torque are thus better captured in a regional analysis (see Part II). We nevertheless present here results for the fifth EOF (Fig. 7c), which has pronounced centers of action over the northeastern Pacific and northern Europe, two important areas of strong LFV (Wallace and Gutzler 1981). EOF-5 accounts for 3.5\% of the year-round variability and is very similar to the second winter hemispheric EOF (not shown). It accounts for $9.6 \%$ of the DJF variability and correlates well with the pattern that gives rise to a large mountain torque at zero lag (Fig. 2). It captures, therefore, a substantial fraction of the $\mathrm{NH}$ winter variability that is associated with mountain torques.

\section{b. PCs and NH mountain torque}

To establish relationships between the NH $T_{M}$ and the leading PCs of the $Z_{700}$ height fields, we carried out a cross-spectral analysis between each PC of interest and the NH mountain torque (Fig. 8). For PC-1, two large and significant peaks in the cross-spectrum (Fig. 8a, upper part of panel) are in the 20-30-day band. The phase angle (Fig. 8a, lower part of panel) shows that, at all IS periodicities, the NH mountain torque is in near-constant quadrature with the changes in PC-1 and leads it throughout. This phase relationship is explained by the near zonally symmetric and meridionaly monotone nature of EOF-1. Any $T_{M}$ anomaly, whichever way it may originate, must therefore lead to a change in $M$ and thus PC-1.

Positive values of the mountain torque imply an eastward acceleration of the atmosphere, while positive values of PC-1 correspond to higher-than-usual midlatitude zonal winds, and thus AAM. In the 20-30-day band, the former lead the latter by about 6-8 days. The amplitudes of the 20-30-day PC-1, extracted by applying to it the 20-30-day bandpass filter of Fig. 4b, are quite substantial: after subtracting the seasonal cycle they account for $22 \%$ of the leading PC's variance (Table 1); in the Central Pacific, between $30^{\circ}$ and $50^{\circ} \mathrm{N}$, this corresponds to variations of typically $2 \mathrm{~m} \mathrm{~s}^{-1}$ in the zonal mean wind at $700 \mathrm{hPa}$.

The cross-spectrum of PC-2 and $\mathrm{NH} T_{M}$ (Fig. 8b), exhibits two highly significant peaks at 22-23 days and 19-20 days, and a slightly less significant one near 31 days. For the two most significant peaks the NH moun-
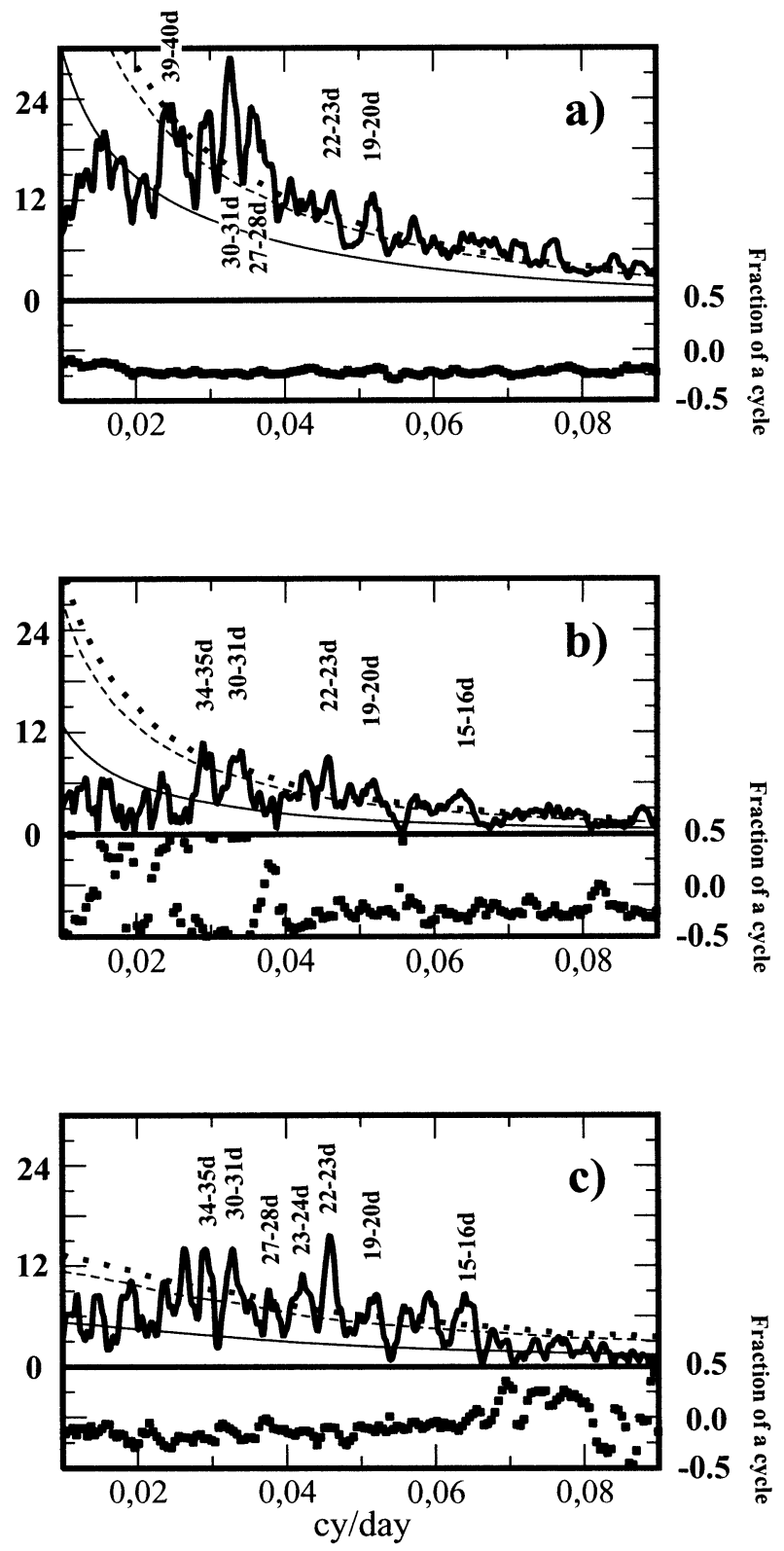

FIG. 8. Cross-spectra between NH $T_{M}$ and the leading NH PC-s: (a) NH $T_{M}$ vs NH PC-1, (b) $\mathrm{NH} T_{M}$ vs NH PC-2, and (c) $\mathrm{NH} T_{M}$ vs NH PC-5. Upper part of panels: cross-spectral amplitude (heavy solid) with $99 \%$ confidence level (heavy dots), 95\% confidence level (light dashed), and median (light solid) of Monte Carlo test. Lower panels: phase difference (filled squares). The cross-spectra are computed from the cross periodogram of the $3 \mathrm{~d}$ series smoothed with the same window as shown in Fig. 3a. All cross-spectral amplitudes are normalized by the NH- $T_{M}$ and PC standard deviation with annual cycle subtracted. For each PC and torque series, the Monte Carlo test uses 100 crossspectra of AR-1 bivariate series that fit the $3 \mathrm{~d}$ series of $\mathrm{NH} T_{M}$ and of the corresponding PC, with annual cycle subtracted.

tain torque again leads the PC in phase quadrature; this indicates that at the corresponding periodicities the mountain torque can affect changes in the Arctic Oscillation. The amplitude of the peaks in the cross-spectrum in Fig. $8 \mathrm{~b}$ is, however, systematically smaller than 

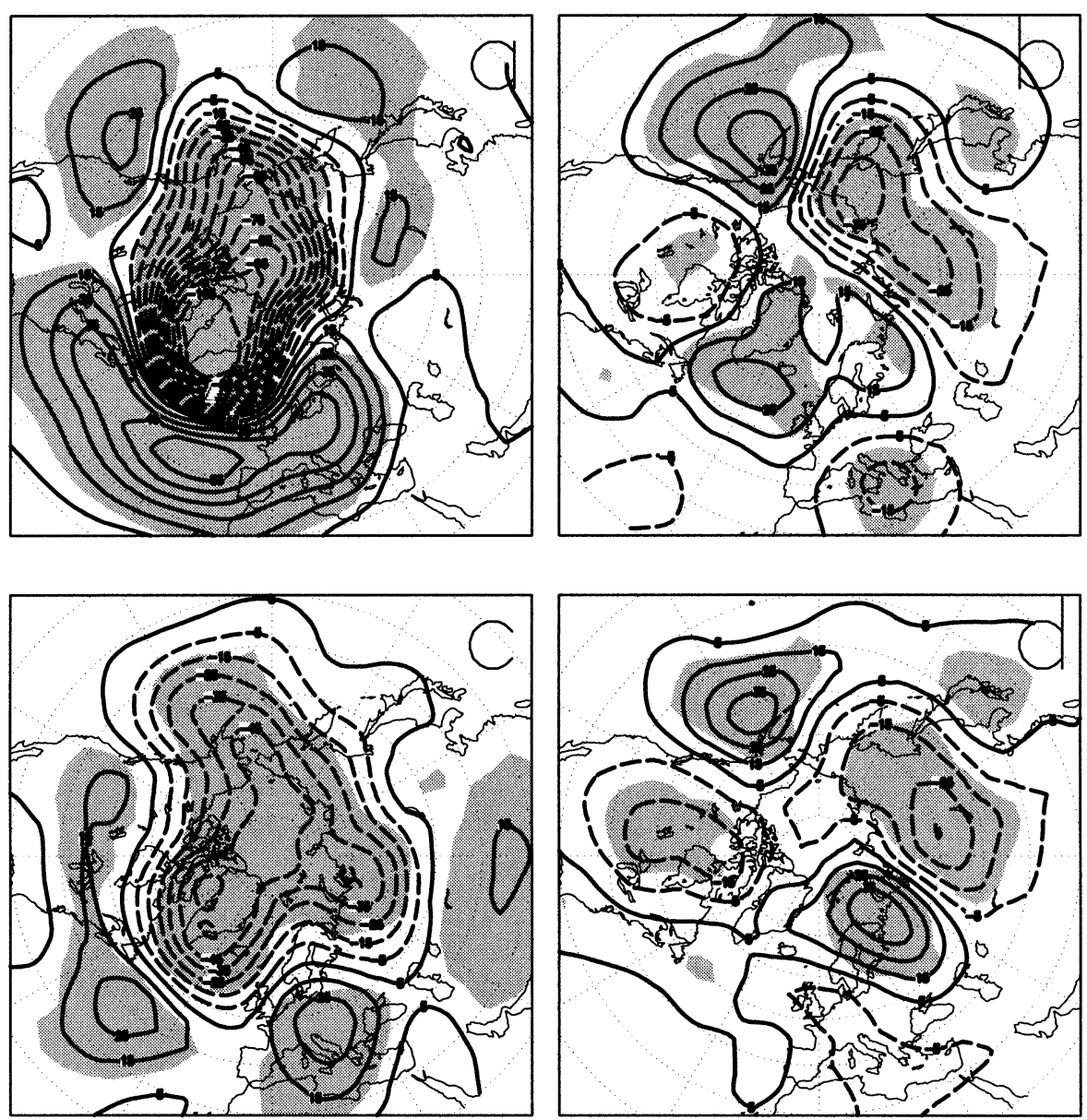

FIG. 9. Composite anomalies of the IS $Z_{700}$ maps keyed to (a), (b) the 20-30-day NH PC-2 and (c), (d) the 20-30-day planetary angular momentum $M_{\Omega}$ : (a), (c) 0-day lag and (b), (d) 6-day lag. Same conventions and parameters as in Fig. 5.

in Fig. 8a, showing that the links between the $\mathrm{NH} T_{M}$ and $\mathrm{PC}-2$ are less pronounced then those between the NH $T_{M}$ and PC-1.

The cross-spectrum of the NH $T_{M}$ and PC-5 (Fig. 8c) exhibits peaks in the 20-30-day band at the same periods as the mountain torque spectrum (Fig. 4a). The phase angle, however, shows that in most circumstances the changes in the NH $T_{M}$ and those of PC-5 are nearly in phase, with the torque leading only by a few days. This in-phase relation is consistent with the spatial pattern of EOF-5 (see again Fig. 7c) that has two very pronounced lows: one to the west of the Rockies and the other to the northwest of the Himalayas (cf. Fig. 2 here and Figs. 2a,b in Part II).

To clarify further the relationships among PC-2, PC5 , and the $\mathrm{NH} T_{M}$, we next filter the $Z_{700}$ variability associated with PC-2 by constructing 20-30-day-filtered time series. The reconstructed 20-30-day series capture a significant fraction of the IS filtered PC-2, typically about $25 \%$ of its variance. We next build composite maps of the IS $Z_{700}$ fields during the 20-30-day cycle of NH PC-2 and plot them in Fig. 9 in the same way as the composites in Fig. 5 for the NH $T_{M}$. The threshold value taken for the bandpass-filtered PC-2 extrema equals $1.3 \sigma_{P 2}$, where $\sigma_{P 2}$ is the standard deviation of the IS series of PC-2. This value ensures that $N_{c}=80$ days are selected for each composite map, the same number as in Fig. 5.

At zero lag with the extrema in PC-2 (Fig. 9a), the composite essentially shows a strong midlatitude jet; its overall pattern is close to the EOF-2 pattern in Fig. 7b. At 6-day lag (Fig. 9b) the strength of the midlatitude jet has substantially decreased, and the composite is characterized by two east-west dipoles, one centered over the Rockies and the second to the north of the western flank of the Tibetan Plateau. These two features correlate with negative $\mathrm{NH} T_{M}$, as they are nearly opposite to the dipole patterns located near the two major mountain ranges in Fig. 2. Note that the composite map at 6-day lag (Fig. 9b) correlates also with the reverse polarity of EOF-5 in Fig. 7c. This suggests that the AO changes in the 20-30-day band can in part be due to the mountain torque, especially when the atmospheric 


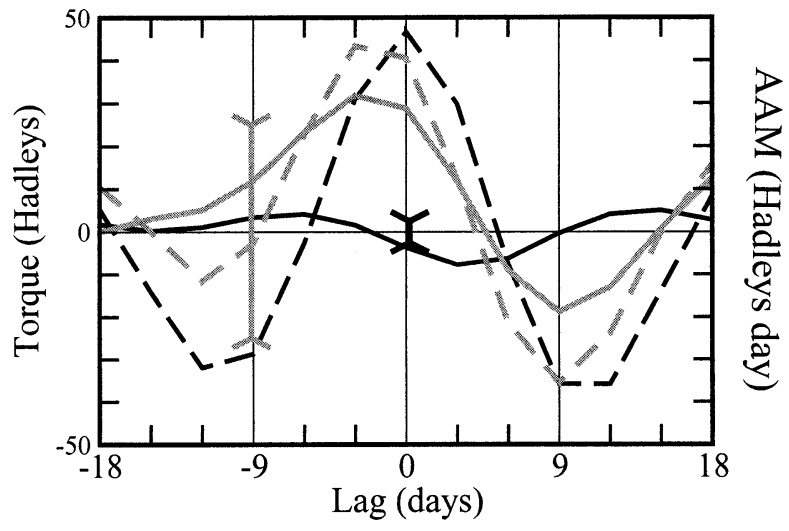

FIG. 10. Composites of different terms in the IS AAM budget keyed to the 20-30-day cycle of the Arctic Oscillation (PC-2 in our analysis): NH $T_{M}$ (black solid), integral of $\mathrm{NH} T_{M}$ (gray solid), global AAM $M$ (gray dashed), and planetary AAM (black dashed). Same conventions and parameters as in Fig. 6.

circulation projects substantially onto the EOF-5 pattern.

To corroborate this finding, Fig. 10 presents the evolution of the IS composites of NH $T_{M}$ (solid black line) and $M$ (gray dashed) during the 20-30-day cycle of PC2 in Fig. 9. The global AAM exhibits a significant maximum of 40-Hd amplitude at zero and at small negative lag. This maximum is of moderate amplitude, compared to the characteristic AAM variations in the IS band, where $\sigma_{M}=100 \mathrm{Hd}$; it is essentially due to a substantial maximum in planetary angular momentum $M_{\Omega}$ (dashed black line), the standard deviation of the IS $M_{\Omega}$ series being $\sigma_{M_{\Omega}}=40 \mathrm{Hd}$. The $\mathrm{NH}$ mountain torque composites have a significant maximum above $4 \mathrm{H}$ at -6 day lag and a significant minimum near $-8 \mathrm{H}$ at +3 day lag. Although moderate when compared to the standard deviation of the IS NH mountain torque $\left(\sigma_{T}=10\right.$ $\mathrm{H})$, the changes in $M$ to be expected from the composite of the NH mountain torque (gray solid in Fig. 10) match quite well in phase and amplitude the composite evolution of $M$ during the 20-30-day variation of PC-2.

Finally, and to check even further that the 20-30-day changes in PC-2 can be associated with certain terms in the AAM budget, Figs. 9c,d show composite of $Z_{700}$ maps during the 20-30-day cycle of planetary angular momentum $M_{\Omega}$. The threshold value taken to form the composites from the 20-30-day series of $M_{\Omega}$ equals $1.4 \sigma_{M_{\Omega}}$; this value again ensures that $N_{c}=80$ maps are selected. At 0-day lag, the map in Fig. 9c essentially shows a deficit of mass almost everywhere north of $50^{\circ} \mathrm{N}$, equilibrated by an excess of mass south of this latitude (including in the Tropics, not shown, but see also Ghil et al. 1991). This redistribution of mass is consistent with $M_{\Omega}$ being positive at that time. At 6-day lag, the map in Fig. 9d correlates well with negative NH $T_{M}$ (reverse polarity of Fig. 2) and with the reverse polarity of EOF-5 in Fig. 7c. The two maps in Figs. 9a,c and the two maps in Figs. 9b,d resemble each other pairwise; this fact suggests that the relationship between PC-5 and PC-2 results from the mountain torque associated with PC-5 modifying the mass angular momentum and hence PC-2.

Since changes in mass distribution in the midlatitudes are related by geostrophy to changes in wind via the geostrophic balance, it is not surprising that, in our dataset, the mountain torque effect at high latitudes is better seen in the mass AAM than in the wind AAM. This aspect of our results does not contradict the fact that a positive torque accelerates the flow.

\section{Summary and discussion}

Using $40 \mathrm{yr}$ of NCEP-NCAR reanalysis data, statistically significant relationships between mountain torques and atmospheric low-frequency variability (LFV) have been demonstrated. Spectral analyses performed on the different terms of the AAM budget show that the dominant IS variations of the mountain torque occur at periods below and close to 30 days (Fig. 3). This result contrasts with many studies of the relative angular momentum $M_{R}$ that have generally discussed variations with either longer or shorter periodicities.

The effect of the MJO on relative angular momentum seems to peak at 50 days (Dickey et al. 1991; Madden and Julian 1994). Thus, the torque variations below 30 days that we find are associated with extratropical oscillations in atmospheric fields. This is consistent with the fact that there are few large mountain ranges in the Tropics, while there are substantial low-frequency oscillations in the extratropics in the 20-30-day band (Branstator 1987; Kushnir 1987; Ghil and Mo 1991).

Bandpass filtering the mountain torque, we have extracted a 20-30-day signal that accounts for nearly $50 \%$ of the $\mathrm{NH}$ mountain torque variations in the IS band. By making composites of 700-hPa geopotential height maps $\left(Z_{700}\right)$ according to the phase of the 20-30-day cycle in NH $T_{M}$, we found them to be associated with statistically significant hemispheric circulation patterns (Fig. 5). The patterns that are in phase with the torque anomalies are characterized by two large-scale eastwest dipoles centered over the Rockies and northwest of the Himalayas, respectively. As each oscillation evolves, the height anomalies become significant over the major LFV centers, especially the central North Pacific and western Europe.

The $Z_{700}$ circulation anomalies acquire a zonally symmetric component when in phase quadrature with the torque oscillations. They are also associated with significant AAM anomalies driven by the NH mountain torque (Fig. 6). These results are consistent with a positive torque anomaly accelerating the zonal wind, which leads to zonally symmetric geopotential height anomalies that are in quadrature with the torque.

To determine to what extent the 20-30-day torque oscillations are related to the dominant NH LFV patterns, we performed a spatial EOF analysis of the $\mathrm{NH}$ 
700-hPa geopotential height variations (Fig. 7). Crossspectra between the NH $T_{M}$ and the leading PCs of NH LFV showed several significant relationships (Fig. 8). The strongest one is between the $\mathrm{NH}$ mountain torque and EOF-1, which describes changes in the midlatitude jet intensity between $30^{\circ}$ and $50^{\circ} \mathrm{N}$ : in the $20-30$-day band, the torque leads PC-1 and is in almost exact phase quadrature with it (Fig. 8a). This suggests that positive torque anomalies accelerate the large-scale flow in midlatitudes and partly drive the 20-30-day zonal-flow variations associated with EOF-1. From minimum to maximum, these oscillations can reach $5 \mathrm{~m} \mathrm{~s}^{-1}$ over the western part of the NH's oceanic basins (not shown). That the mountain torques can partly drive these changes in the large-scale circulation is further supported by the EOF-1 pattern having a high degree of zonal symmetry (see Fig. 7a); it is thus very different from flow patterns that would produce a large mountain torque per se (Fig. 2).

For the other leading hemispheric PCs, the relationships are not as strong but are nevertheless significant (Figs. 8b,c). Changes in the torque often anticipate those in PC-2, suggesting that mountain forcing can contribute to the evolution of the Arctic Oscillation (see Fig. 7b). For this PC, the lead-lag relationships in Figs. 9 and 10 indicate that the 20-30-day cycle in PC-2 is accompanied by moderate but significant changes in global AAM that are driven by the NH mountain torque. These changes in $M$ are essentially due to changes in $M_{\Omega}$, as found by von Storch (1999) in GCM experiments. Consistent with this result, the $Z_{700}$ fields in quadrature with the 20-30-day PC-2 (Fig. 9b) and with the 20-30-day $M_{\Omega}$ (Fig. 9d) correlate well with the pattern associated with large NH mountain torques at zero lag (Fig. 2). These $Z_{700}$ fields also correlate well with EOF-5 (Fig. $7 \mathrm{c}$ ), indicating that the evolutions of PC-2 and PC-5 are linked with each other via the $\mathrm{NH}$ mountain torque and the planetary angular momentum.

One theory of midlatitude LFV (Charney and DeVore 1979) suggests that mountain torques play an important role in the nonlinear dynamics of the atmosphere. According to this theory, when the large-scale flow is blocked (zonal), the Rossby waves forced by the topography have large (small) amplitude and thus lead to a strong (weak) mountain torque being exerted on the mean flow. In the large-scale NH atmosphere, where wave-wave interaction plays an important role, blocked and zonal flow can still occur as distinct phases of oscillatory spells (Legras and Ghil 1985; Yoden 1985; Ghil 1987), rather than as distinct stable equilibria. For such spells to occur the zonal-flow amplitude (proportional to $M$ ) and the mountain torque $\left(T_{M}\right)$ have to be in quadrature, at least when the dissipation is small. Our diagnostic calculations imply that such relationships between torques and zonal flow may exist in the $\mathrm{NH}$ midlatitudes. They allow us to suggest that mountain torques partly drive changes in EOF-1 and in the Arctic Oscillation in the 20-30-day band.
In Part II of this study we examine the more regional aspects of NH LFV and their connection to the torques induced by the individual mountain ridges. We also consider the episodic, or intermittent, aspects of LFV in this context.

Acknowledgments. The authors are grateful to past and present associates on three continents for interesting exchanges on low-frequency atmospheric variability. The NCEP-NCAR reanalysis data are provided through the NOAA Climate Diagnostics Center (http://www. cdc.noaa.gov). Extensive and persistent comments by Klaus M. Weickmann and two anonymous referees have greatly improved the presentation of our results. Our work was supported by NASA Grant NAG5-9294 (FL), DOE Grant DE-FG03-01ER63260 (AWR) and NSF Grant ATM-0082131 (MG). This is publication 5836 of UCLA's Institute of Geophysics and Planetary Physics.

\section{REFERENCES}

Bernardet, P., A. Butet, M. Déqué, M. Ghil, and R. L. Pfeffer, 1990: Low-frequency oscillations in a rotating annulus with topography. J. Atmos. Sci., 47, 3023-3043.

Blackmon, M. L., 1976: A climatological study of the $500 \mathrm{mb}$ geopotential height of the Northern Hemisphere. J. Atmos. Sci., 33, $1607-1623$.

— Hemisphere wintertime circulation: A comparison of the simulation of the GFDL general circulation model with observations. J. Atmos. Sci., 37, 497-514.

Branstator, G., 1987: A striking example of the atmosphere's leading traveling pattern. J. Atmos. Sci., 44, 2310-2323.

Charney, J. G., and A. Eliassen, 1949: A numerical method for predicting the perturbations of the middle latitude westerlies. Tellus, 1, 38-54.

— mosphere and blocking. J. Atmos. Sci., 36, 1205-1216.

Cheng, X., and J. M. Wallace, 1993: Cluster analysis of the Northern Hemisphere wintertime 500-hPa height field: Spatial patterns. $J$. Atmos. Sci., 50, 2674-2696.

Dickey, J. O., M. Ghil, and S. L. Marcus, 1991: Extratropical aspects of the 40-50 day oscillation in length-of-day and atmospheric angular momentum. J. Geophys. Res., 96, 22 643-22 658.

Egger, J., and K. P. Hoinka, 2002: Equatorial components of global atmospheric angular momentum: Covariance functions. Quart. J. Roy. Meteor. Soc., 128, 1137-1157.

Ghil, M., 1987: Dynamics, statistics and predictability of planetary flow regimes. Irreversible Phenomena and Dynamical Systems Analysis in the Geosciences, C. Nicolis and G. Nicolis, Eds., D. Reidel, 241-283.

— mosphere. Part I: Northern Hemisphere and tropics. J. Atmos. Sci., 48, 752-779.

— S. L. Marcus, J. O. Dickey, and C. L. Keppenne, 1991: AAM the Movie. NTSC Videocassette AVC-91-063, Caltech/NASA Jet Propulsion Laboratory, Pasadena, CA.

Hamming, R. W., 1983a: Smooth nonrecursive filters. Digital Filters, Prentice Hall, 150-163.

_ 1983 b: Kaiser windows and optimization. Digital Filters, Prentice Hall, 185-207.

Held, I. M., 1983: Stationary and quasi-stationary eddies in the extratropical troposphere: Theory. Large-Scale Dynamical Processes in the Atmosphere, B. J. Hoskins and R. P. Pearce, Eds., Academic Press, 127-168. 
Hendon, H. H., 1995: Length of day changes associated with the Madden-Julian oscillation. J. Atmos. Sci., 52, 2373-2383.

Hoskins, B. J., and D. J. Karoly, 1981: The steady linear response of a spherical atmosphere to thermal and orographic forcing. $J$. Atmos. Sci., 38, 1179-1196.

— , and P. J. Valdes, 1990: On the existence of storm tracks. $J$. Atmos. Sci., 47, 1855-1864.

- I. N. James, and G. H. White, 1983: The shape, propagation and mean-flow interaction of large-scale weather systems. $J$. Atmos. Sci., 40, 1595-1612.

Huang, H. P., P. D. Sardeshmukh, and K. M. Weickmann, 1999: The balance of global angular momentum in a long-term atmospheric data set. J. Geophys. Res., 104, 2031-2040.

Illari, L., and J. C. Marshall, 1983: On the interpretation of eddy fluxes during a blocking episode. J. Atmos. Sci., 40, 2232-2242.

Iskenderian, H., and D. A. Salstein, 1998: Regional sources of mountain torque variability and high-frequency fluctuations in atmospheric angular momentum. Mon. Wea. Rev., 126, 16811694.

Jin, F.-F., and M. Ghil, 1990: Intraseasonal oscillations in the extratropics: Hopf bifurcation and topographic instabilities. J. Atmos. Sci., 47, 3007-3022.

Kalnay, E., and Coauthors, 1996: The NCEP/NCAR 40-Year Reanalysis Project. Bull. Amer. Meteor. Soc., 77, 437-472.

Kimoto, M., and M. Ghil, 1993a: Multiple flow regimes in the Northern Hemisphere winter. Part I: Methodology and hemispheric regimes. J. Atmos. Sci., 50, 2625-2643.

_ and _ $1993 \mathrm{~b}$ : Multiple flow regimes in the Northern Hemisphere winter. Part II: Sectorial regimes and preferred transitions. J. Atmos. Sci., 50, 2645-2673.

Kushnir, Y., 1987: Retrograding wintertime low-frequency disturbances over the North Pacific Ocean. J. Atmos. Sci., 44, $2727-$ 2742.

Legras, B., and M. Ghil, 1985: Persistent anomalies, blocking and variations in atmospheric predictability. J. Atmos. Sci., 42, 433471.

Lejenäs, H., and R. A. Madden, 2000: Mountain torques caused by normal-mode global Rossby waves, and the impact on atmospheric angular momentum. J. Atmos. Sci., 57, 1045-1051.

Lott, F., 1999: Alleviation of stationary biases in a GCM through a mountain drag parameterization scheme and a simple representation of mountain lift forces. Mon. Wea. Rev., 127, 788-801.

— A. W. Robertson, and M. Ghil, 2001: Mountain torques and atmospheric oscillations. Geophys. Res. Lett., 28, 1207-1210.

,$- \ldots$, and — 2004: Mountain torques and Northern Hemisphere low-frequency variability. Part II: Regional aspects. $J$. Atmos. Sci., 61, 1272-1283.

Madden, R. A., 1987: Relationship between changes in the length of day and the 40 to 50 day oscillation in the tropics. J. Geophys. Res., 92, 8391-8399.

— in the zonal wind in the tropical Pacific. J. Atmos. Sci., 28, 702708.

$\longrightarrow$, and — 1994: Observations of the 40-50-day tropical oscillation-A review. Mon. Wea. Rev., 122, 814-837.

- , and P. Speth, 1995: Estimates of atmospheric angular momentum, friction, and mountain torques during 1987-1988. J. Atmos. Sci., 52, 3681-3694.

Marcus, S. L., M. Ghil, and J. O. Dickey, 1994: The extratropical 40-day oscillation in the UCLA general circulation model. Part II: Atmospheric angular momentum. J. Atmos. Sci., 51, 14311446.

,$- \ldots$, and $—, 1996$ : The extratropical 40-day oscillation in the UCLA general circulation model. Part II: Spatial structure. J. Atmos. Sci., 53, 1993-2014.

Metz, W., 1985: Wintertime blocking and mountain forcing of the zonally averaged flow: A cross-spectral time series analysis of observed data. J. Atmos. Sci., 42, 1880-1892.

Mo, K., and M. Ghil, 1987: Statistics and dynamics of persistent anomalies. J. Atmos. Sci., 44, 877-901.

Molteni, F., A. Sutera, and N. Tronsi, 1988: The EOFs of the geopotential eddies at $500 \mathrm{mb}$ in winter and their probability density distributions. J. Atmos. Sci., 45, 3063-3080.

— - S. Tibaldi, and T. Palmer, 1990: Regimes in the wintertime circulation over northern extratropics. Part I: Observational evidence. J. Atmos. Sci., 47, 31-67.

Papoulis, A., 1973: Minimum bias windows for high resolution spectral estimates. IEEE Trans. Inf. Theory, 19, 9-12.

Penland, C., M. Ghil, and K. M. Weickmann, 1991: Adaptive filtering and maximum entropy spectra with application to changes in atmospheric angular momentum. J. Geophys. Res., 96, 22 65922671.

Plaut, G., and R. Vautard, 1994: Spells of low-frequency oscillations and weather regimes in the Northern Hemisphere. J. Atmos. Sci., 51, 210-236.

Preisendorfer, R. W., 1988: Principal Component Analysis in Meteorology and Oceanography. Elsevier Science, 425 pp.

Sawyer, J. S., 1976: Observational characteristics of atmospheric fluctuations with a time scale of a month. Quart. J. Roy. Meteor. Soc., 102, 610-625.

Scavuzzo, C. M., M. A. Lamfri, H. Teitelbaum, and F. Lott, 1998: A study of the low frequency inertio-gravity waves observed during PYREX. J. Geophys. Res., 103, 1747-1758.

Simmons, A. J., J. M. Wallace, and G. W. Branstator, 1983: Barotropic wave propagation and instability and atmospheric teleconnections patterns. J. Atmos. Sci., 40, 1363-1392.

Thompson, D. W., and J. M. Wallace, 1998: The Arctic Oscillation signature in the wintertime geopotential height and temperature fields. Geophys. Res. Lett., 25, 1297-1300.

Tian Y., E. Weeks, K. Ide, J. S. Urbach, C. N. Baroud, M. Ghil, and H. L. Swinney, 2001: Experimental and numerical studies of an eastward jet over topography. J. Fluid. Mech., 438, 129-157.

Valdes, P. J., and B. J. Hoskins, 1991: Nonlinear orographically forced planetary waves. J. Atmos. Sci., 48, 2089-2106.

Vautard, R., B. Legras, and M. Déqué, 1988: On the source of midlatitude low-frequency variability. Part I: A statistical approach to persistence. J. Atmos. Sci., 45, 2811-2843.

von Storch, J.-S., 1994: Interdecadal variability in a global coupled model. Tellus, 46A, 419-432.

__ 1999: The reddest atmospheric modes and the forcing of the spectra of these modes. J. Atmos. Sci., 56, 1614-1626.

Wallace, J. M., 2000: North Atlantic Oscillation/annular mode: Two paradigms-One phenomenon. Quart. J. Roy. Meteor. Soc., 126, 791-806.

- , and D. S. Gutzler, 1981: Teleconnections in the geopotential height field during the Northern Hemisphere winter. Mon. Wea. Rev., 109, 784-812.

Weeks, E. E., Y. Tian, J. S. Urbach, K. Ide, H. L. Swinney, and M. Ghil, 1997: Transitions between blocked and zonal flows in a rotating annulus with topography. Science, 278, 1598-1601.

Weickmann, K. M., S. J. S. Khalsa, and J. Eischeid, 1992: The atmospheric angular momentum cycle during the tropical Madden-Julian oscillation. Mon. Wea. Rev., 120, 2252-2263.

_- W. A. Robinson, and C. Penland, 2000: Stochastic and oscillatory forcing of global atmospheric angular momentum. J. Geophys. Res., 105 (D12), 15 543-15 557.

Yoden, S., 1985: Multiple stable states of quasi-geostrophic barotropic flow over sinusoidal topography. J. Meteor. Soc. Japan, 63, 1031-1045. 